\title{
Giant Cell Arteritis Involving the Mesenteric Arteries
}

MAHA ABDUL AZEEZ, MB, BCh, MRCPI; PETER BROWNE, MB, BCh, MMdSC, MRCPI; PAUL O'CONNELL, MB, BCh, FRCPI; DERVAL ROYSTEN, MB, BSc, FRCPath, Department of Rheumatology, Beaumont Hospital, Beaumont Road, Dublin, D9, Republic of Ireland. Address correspondence to Dr. Azeez. E-mail: mahaazeez@hotmail.com. J Rheumatol 2009;36:2314-5; doi.10.3899/jrheum.090152

Giant cell arteritis (GCA) involving the mesenteric arteries is diagnosed rarely and a limited number of cases have been reported $^{1}$. It is only recognized when symptoms of bowel ischemia occur in a suitable setting. We describe a case where the diagnosis was made serendipitously at the time of a partial colectomy.

A 78-year-old man presented with 3-month history of anemia $(10 \mathrm{~g} / \mathrm{dl})$, weight loss, and general malaise. He denied any focal bowel symptoms, and examination was unremarkable. Blood investigations revealed markedly elevated liver function tests (LFT) with gamma-glutamyl transferase and alkaline phosphatase over $800 \mathrm{IU} / \mathrm{l}$, elevated erythrocyte sedimentation rate $(\mathrm{ESR})>100 \mathrm{~mm} / \mathrm{h}$, and C-reac- tive protein $(\mathrm{CRP})>100 \mathrm{mg} / \mathrm{l}$. Colonoscopy performed because of anemia revealed a cecal tumor, which was fully resected (Figure 1). Histology confirmed a moderately differentiated cecal adenocarcinoma (pT3, N0). There was an incidental finding of GCA involving the media and intima in a number of mesenteric arteries (Figure 2).

Symptoms, ESR, and LFT remained unchanged 6 weeks postsurgery. On direct questioning the patient reported some vague left-side temporal headache. He began taking prednisolone $60 \mathrm{mg}$ daily, with rapid improvement in wellbeing. Within a month ESR, CRP, and LFT had normalized.

GCA classically affects vessels originating from the arch of the aorta; it may involve any large to medium-size blood
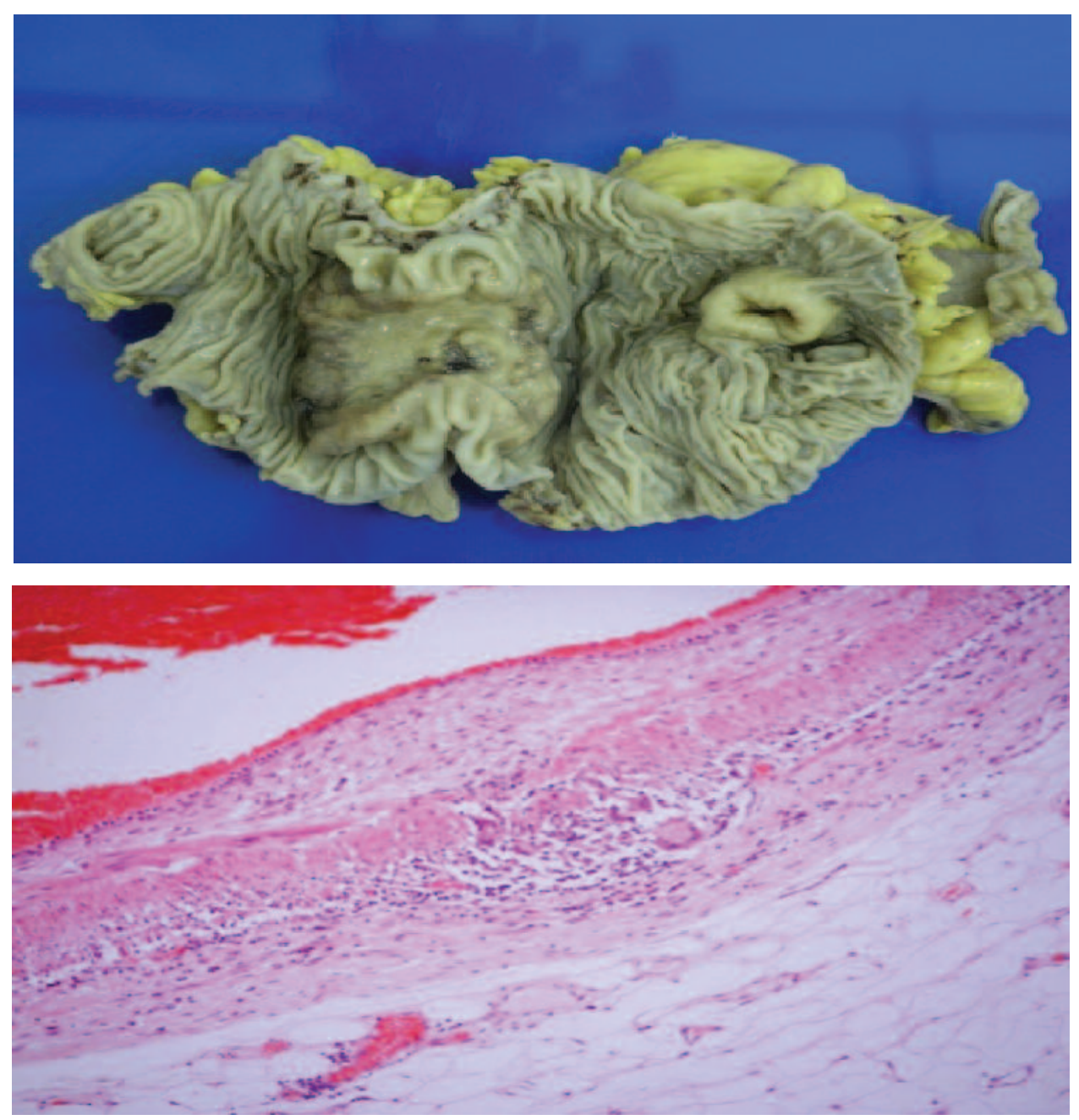

Figure 1. Gross specimen of the resected cecum with ileocecal valve visible on the right and polypoid tumor, $4.5 \mathrm{~cm}$ diameter, with rolled edges visible on the left side.

Figure 2. Longitudinal section of mesenteric artery with an inflammatory arteritis with giant cells arising in the media and extending to the intima of the artery (original magnification $\times 40$. 
vessel. Anemia and abnormal LFT, especially alkaline phosphatase, are common. Mesenteric involvement is extremely rarely recognized. A recent review of the English language literature reported 12 cases of mesenteric ischemia attributed to $\mathrm{GCA}^{1}$. Our patient had no gastrointestinal (GI) symptoms and the recognition of mesenteric arteritis was made due to surgery for an incidental bowel cancer found during investigation of his anemia. He did, however, have systemic symptoms in keeping with GCA, which responded rapidly to corticosteroids. The lack of GI symptoms in GCA probably relates to the extensive collateral splanchnic circulation, which would prevent ischemia. The diagnosis of cecal carcinoma was a fortuitous result of investigations for malaise, weight loss, and anemia, most likely due to the underlying GCA.

\section{REFERENCE}

1. Scola CJ, Li C, Upchurch KS. Mesenteric involvement in giant cell arteritis. An underrecognised complication? Analysis of a case series with clinicoanatomic correlation. Medicine (Baltimore) 2008;87:45-51. 